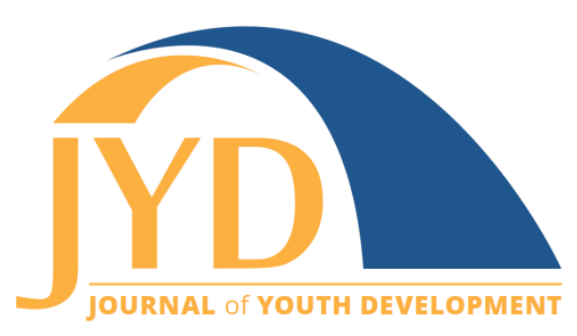

http://jyd.pitt.edu/ | Vol. 16 Issue 5 DOI 10.5195/jyd.2021.1068 | ISSN 2325-4017 (online)

\title{
The Complexities of Student Engagement for Historically Marginalized Youth in an After-School Program
}

\author{
Ashlee L. Sjogren \\ University of Virginia, Youth-Nex \\ am/6qc@virginia.edu \\ Theresa N. Melton \\ University of Guam \\ tnm2ff@virginia.edu
}

\begin{abstract}
As researchers continue to address issues of equity within educational settings, it is important to also consider the role of equity in high-quality after-school programs. Evidence suggests that families from communities with fewer resources, along with families that identify as Black or Hispanic, report less access to quality after-school programming for their youth (Afterschool Alliance, 2020). This is especially problematic, as after-school programming has been associated with a number of positive outcomes for youth. In this study, researchers highlight youth perspectives to illuminate the challenges related to engaging historically marginalized youth in a school-based after-school program. Findings suggest that youth from marginalized backgrounds typically discuss engagement in terms of behavioral and affective experiences. Further, youth identified a few barriers to engagement, including repetition of program content and disruptive behavior. As a result of these findings, researchers suggest that practitioners integrate youth perspectives, work collaboratively to develop curriculum that fosters growth, and adopt policies and training that support staff in implementing culturally appropriate discipline approaches in after-school programs.
\end{abstract}

Key words: engagement, historically marginalized youth, after-school programs

\section{Introduction}

The results of several studies have highlighted that students face many challenges to equity in formal education. Evidence of inequity include the persistence of achievement gaps (Vanneman et al., 2009), opportunity gaps (Flores, 2007), and disproportionate discipline seen by youth of color compared to their White peers (Skiba et al., 2002). However, although seldom the topic of

(cc) EY New articles in this journal are licensed under a Creative Commons Attribution 4.0 License. This journal is published by the University Library System, University of Pittsburgh and is cosponsored by the University of Pittsburgh Press. The Journal of Youth Development is the official peer-reviewed publication of the National Association of Extension 4-H Youth Development Professionals and the National AfterSchool Association. 
research, inequitable access to quality education is present in after-school programs as well, and this unequal access is just as much an issue of civil rights (Afterschool Alliance, 2020; Carver \& Iruka, 2006). Recent reports suggest that families from communities with fewer financial resources are more likely to report a lack of access to quality after-school programming (Afterschool Alliance, 2020). Further, families who identify as Black or Hispanic report similarly low levels of access (Afterschool Alliance, 2020). This trend continues into participation rates where students from lower socioeconomic backgrounds report lower participation in after-school activities (Mahoney et al., 2009). Instead of working to decrease the racial and economic gaps in education, these after-school programs reflect similar disparities.

These disparities are problematic, given that participation in after-school programming has been associated with decreased problem behavior (Durlak et al., 2010) and increased achievement (Durlak et al., 2010; Lauer et al., 2006). Lauer and colleagues (2006) suggest that after-school programs can be particularly supportive for youth from historically marginalized communities, further highlighting the importance of engaging these students in high-quality programs that support their continued development. Additionally, the lack of access to after-school programs for individuals from communities of concentrated poverty and historically marginalized racial and ethnic populations limits how well researchers can examine the impact that after-school programs have on youth outcomes (Deutsch, 2017). Research suggests that after-school programs are associated with positive outcomes, but the lack of engagement with youth from historically marginalized populations prevents researchers from being able to generalize findings to youth from diverse populations.

\section{Role of Race and Ethnicity in Participation}

When discussing the ways in which programs meet the needs of youth from historically marginalized populations, it is important to consider that one's social identity influences their experiences and development. Ecological systems theories have established the central role of bidirectional relationships between individuals and their environments (Bronfenbrenner, 1994). Development is driven by these interactions within one's immediate environment, often referred to as proximal processes, along with more distal aspects of one's environment, such as political, social, and cultural norms.

Race and ethnicity are central aspects of these person-context relations, reflecting the impact of discrimination, oppression, and segregation (García Coll \& Szalacha, 2004; Spencer, 2008). An individual's racial, ethnic, and cultural background is related to their access to resources, the 
chance they will experience discrimination or racism, and how they define and experience programming (Kochanek \& Erickson, 2020; Williams \& Deutsch, 2016). One's social identity can also impact an individual's decision to engage in a program at all, as youth are less likely to engage in programming if it is viewed as unwelcoming (Ma et al., 2020). Further, programmatic practices can create unwelcoming spaces, even if staff are not aware. Youth from historically marginalized communities have reported experiences of microaggressions, discrimination, and a lack of support within youth programming (Gast et al., 2017). For example, in a study of 204 Latinx adolescents, researchers found that these experiences of discrimination negatively impacted youth engagement and limited positive outcomes associated with program participation (Ma et al., 2020). Therefore, in order to develop contexts that engage youth from historically marginalized communities and promote positive outcomes, the social identity of participants must be considered, and programs must examine the ways in which their policies and practices are influencing the experiences of youth from historically marginalized backgrounds.

Figure 1. Williams and Deutsch (2016) Model Linking Social Identity and MacroLevel Factors in the Context of a Youth Development Program

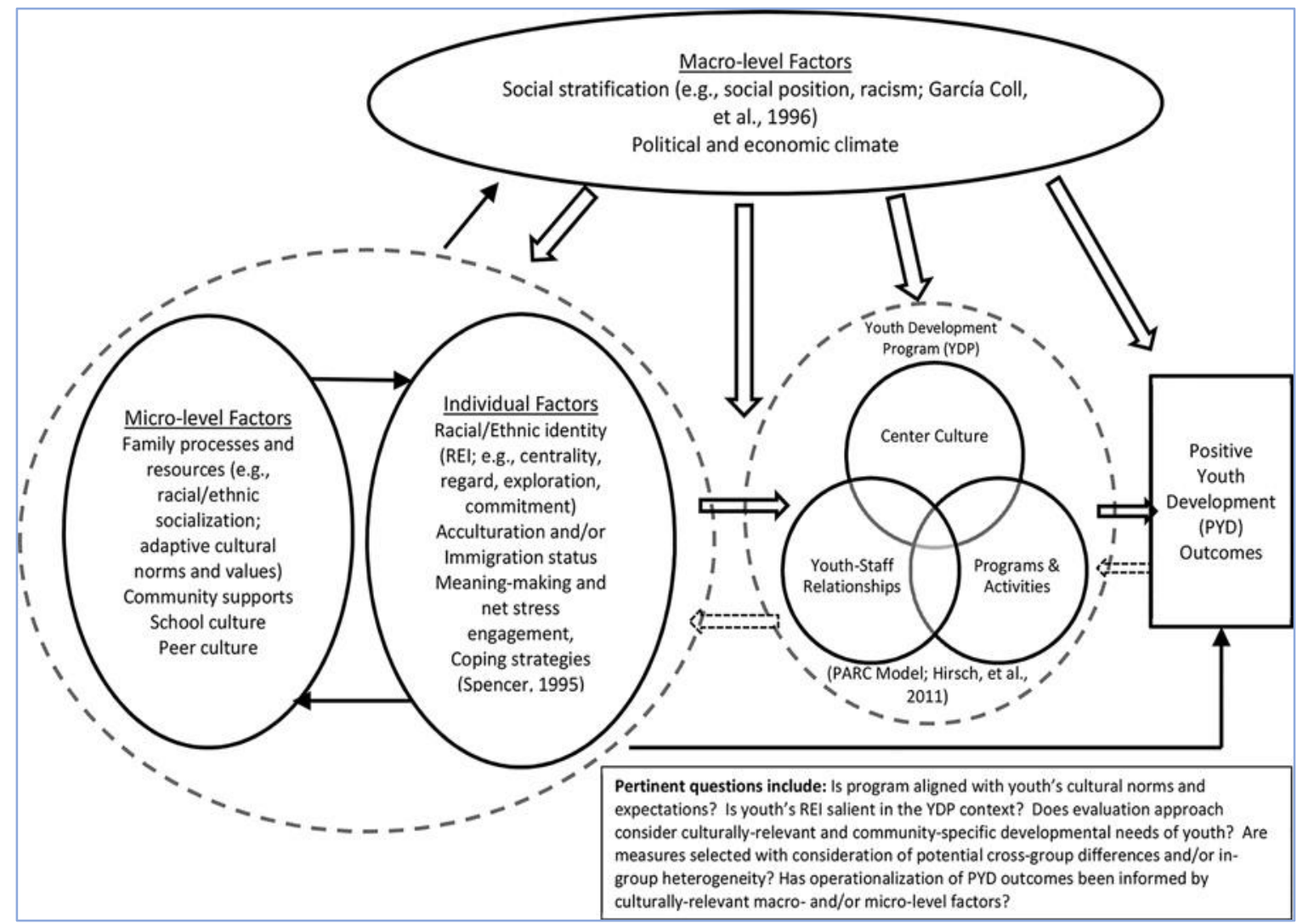


Williams and Deutsch (2016) have proposed an ecological model that connects an individual's social identity and positive development within the context of youth programming (Figure 1). Within this model, characteristics of the individual influence the interactions that occur within the program, and these interactions are influenced by macro-level factors such as social position, experiences of racism, and the broader political and economic climate in which youth live. Furthermore, aspects of the program itself, such as the classes and activities made available, relationships with staff, and the culture of the organization, influence the way in which individuals engage with programming.

\section{Importance of Engagement}

According to Hill and Vance (2019), "a tenet of the out-of-school time (OST) field is that all youth deserve impactful and engaging learning experiences. Organizations, programs, and professionals must be responsive to the existing and emerging needs of the increasingly diverse children and youth that they serve and the communities in which they live" (p. 3). Thus, engagement of all youth should serve as a critical consideration in programmatic decision making. Engagement in programming moves beyond basic participation and captures students' active experiences in after-school programs. For example, measures of participation include the number of days a student shows up to the program, whereas measures of engagement include students' on-task behaviors, feelings of belongingness, and depth of relationships with staff and peers. Additionally, engagement has not only been considered a critical step for students to take in order to achieve positive programmatic outcomes (Finn 1989, 1993; Fredricks et al., 2004), but engagement has also been associated with a host of outcomes, including math achievement and positive developmental outcomes in samples of youth from historically marginalized communities (Sjogren, Zumbrunn, et al., 2021).

In light of these findings, we center this work around understanding students' engagement experiences in their after-school programming. Thus, we adopt the multi-dimensional framework of engagement (Wang et al., 2016), where engagement is understood as the combination of social, affective, cognitive, behavioral, and global elements of a student's experience. Behavioral engagement is what we most commonly think of in terms of engagement; it includes showing up, paying attention, and obeying rules and norms (Fredricks \& McColskey, 2012). Cognitive engagement builds on behavioral engagement to capture the experience of exerting cognitive energy and self-regulation to comprehend and participate in an activity (Wang et al., 2016). Affective engagement refers to the positive and negative emotions that are experienced during an activity that relate to student interest in the activity (Wang et 
al., 2016). Finally, social engagement considers the interpersonal aspects of activities and the depth of relationships that youth develop (Wang et al., 2016). Together these individual components of engagement move beyond a general or global experience of engagement to illuminate the various experiences youth have in their informal learning contexts. Further, these specific dimensions of engagement may be particularly important for adolescents who place a heightened importance on friends (e.g., social engagement), autonomy, and belonging (e.g., affective engagement).

Using this framework of engagement, we believe it is possible to reveal the different ways in which students engage in after-school programs, and what factors serve as barriers to forms of engagement most associated with positive outcomes. It is critical to note that inequitable access to programming can occur at both the physical and psychological level, highlighting the importance of investigating both the tangible (i.e., transportation, scheduling) and psychological (i.e., motivation, belonging) barriers to engagement. Knowledge of these barriers can support programs in promoting engagement amongst their diverse student population, ultimately promoting positive developmental outcomes for these youth (Lauer et al., 2006; Sjogren, Zumbrunn, et al., 2021).

\section{The Present Study}

As part of a larger mixed-methods research project investigating youths' experiences of engagement in out-of-school-time (OST) programs, the present work seeks to highlight youth perspectives and illuminate challenges that arise in relation to engaging racially minoritized students in an after-school program. The goal of this research is to understand the engagement experiences of youth from communities who often face opportunity and access gaps to highquality after-school programming. Drawing on Wang and colleagues' (2016) framework of engagement, we highlight student-reported barriers to engagement using youth perspectives. Then we consider programmatic supports to mitigate these barriers. We seek to answer the following research questions through this work.

1. What are the experiences of engagement in an after-school program for youth from historically marginalized populations?

2. What barriers to engagement do students from historically marginalized communities face in an after-school program? 


\section{Methods}

\section{Program Site}

This work was conducted in partnership with an after-school system, Starters, which provides comprehensive after-school programming for middle school students in one low-income school district. Starters is a wrap-around program, running Monday through Friday, that provides students with dinner, transportation, and a variety of activities such as sports/wellness classes and enrichment activities. Students elect into the courses that most interest them, participating in one or two blocked classes per day. Example blocks/classes include robotics, yoga, Money Matters Club, video game design, and volleyball. As part of a larger research project, this afterschool program was interested in investigating how to best engage and support their participants, most of whom live in historically marginalized communities.

\section{Sample}

Participants were recruited in partnership with youth workers at the program site. Youth participants represented a diverse group of students who differentially engaged in program activities. Students were selected for focus groups using quantitative analyses that identified different engagement profiles based on their response to an after-school engagement scale (see Sjogren, Bae, et al., 2021 for an explanation of the sampling). In total, 18 youth took part in six semi-structured focus group interviews. Given programmatic timing limitations, focus groups were intentionally small, ranging from two to four students per group. The majority of students identified as Black (88.9\%; 16 students), with approximately $11 \%$ identifying as Latinx. Just over half of the participating students identified as male (55.6\%), and student grade level varied across the focus groups with the 33\% of students in Grade 6, 22\% in Grade 7, and $44 \%$ in Grade 8.

\section{Procedures}

The first author conducted six separate focus groups asking students about their engagement experiences in their after-school program. Sample focus group items included: "What do you think is most engaging about Starters?" and "What makes it difficult for you to engage in Starters?" Thus, items were developed to understand students' experiences of engagement as well as what hinders those experiences. Each focus group was conducted during program hours (i.e., dinner, break) and in a private room at the program site. On average, focus group interviews lasted between 20 and 25 minutes, and students were asked to participate in only one focus group. 


\section{Analysis}

Each focus group was audio-recorded and subsequently transcribed with pseudonyms to ensure complete confidentiality for the participating youth. We then used a dual coding process where transcripts were simultaneously analyzed both inductively and deductively, drawing on existing literature as well as systematic readings of each transcript. A priori codes from the literature included the four dimensions of the engagement framework (Wang et al., 2016), whereas open coding resulted in the development of codes such as student autonomy and interpersonal tensions. We then used this codebook to systematically code each of the six transcripts (Onwuegbuzie et al., 2012) using Dedoose software (Version 8.0.44). From this coding, we developed the themes that were presented to program staff to evaluate how well they aligned with staff observations.

\section{Results}

A detailed discussion of the findings from this paper is available at Sjogren, Bae, and colleagues (2021) and are briefly summarized below. The current paper focuses on the implications of these results for youth from historically marginalized backgrounds, and highlights recommendations for the development of equitable after-school spaces that promote the engagement of all students, especially those from historically marginalized backgrounds. Overall, the findings of the qualitative analysis resulted in information related to both the ways in which youth experienced programming and critical barriers that prevented engagement. We discuss those in turn below before focusing on implications for improved work in youth development programs in the discussion.

\section{Youth Engagement Experiences}

Findings across the focus groups highlight that youth from marginalized backgrounds engage in after-school programs in various ways, most frequently conceptualizing this engagement in terms of the affective and behavioral dimensions of engagement. Definitions and examples of each of these dimensions of engagement are provided below as well as in Table 1. 
Table 1. Engagement Experiences in After-School Spaces

\begin{tabular}{|c|c|c|}
\hline & Definition & Exemplar quote \\
\hline $\begin{array}{l}\text { Affective } \\
\text { Engagement }\end{array}$ & $\begin{array}{l}\text { Students explain the positive and } \\
\text { negative emotions related to engaging in } \\
\text { the after-school space. }\end{array}$ & $\begin{array}{l}\text { It's like fun and exciting because you are } \\
\text { doing stuff that you love. }\end{array}$ \\
\hline $\begin{array}{l}\text { Behavioral } \\
\text { Engagement }\end{array}$ & $\begin{array}{l}\text { Students discuss engagement in terms of } \\
\text { attendance, on-task behavior, and } \\
\text { following directions. }\end{array}$ & $\begin{array}{l}\text { Most people, like they don't even . . . they } \\
\text { don't like their class, they just don't come. }\end{array}$ \\
\hline
\end{tabular}

\section{Affective Engagement}

Youth regularly highlighted the emotions they experienced in the after-school space such as happiness, fun, and excitement. When asked what it felt like to be engaged in the after-school space, one student responded, "when you come you really feel really hyped and happy that you [are] here, or something." Another suggested that they engage in activities that "are more interesting so you learn new things." In this way, participating in the program evoked positive feelings for students. These positive feelings around school-based after-school programs are particularly important for youth from historically marginalized backgrounds who experience declines in school connectedness and belonging as they move into adolescence (Gray et al., 2018; Hughes et al., 2017). Thus, this form of affective engagement may have the potential of contributing to positive educational experiences and increased school connectedness.

\section{Behavioral Engagement}

Youth also regularly discussed engagement in terms of the behavioral dimension, highlighting actions such as attending, participating, and following directions. When asked to reflect on the difference between a student who is engaged and one who is not, one youth responded, "A student that's less engaged [doesn't] participate, or they don't follow directions. But a student that is engaged follows directions and participates and asks questions." Similarly, another student shared:

Like, when somebody is really excited, like they want to come to Starters every single day, they want to participate in the field trips every Friday. And then, a person who's not there . . . don't come like faking sick to not come to Starters, or don't want to go on the field trips. 
This resonates with the adage that "students vote with their feet," emphasizing the role that autonomy plays in youth engagement decisions in adolescence. Youth's reliance on behavioral indicators when they conceptualize their engagement experiences demonstrates the importance of program activities that encourage active participation (i.e., group work, play). Taken together, youth seem to emphasize program activities that excite them and encourage active participation.

\section{Barriers to Engagement}

Students reported two key barriers, namely repetition of program content and student behavior. Definitions and examples of each of these barriers are provided below as well as in Table 2 .

Table 2. Barriers to Student Engagement

\begin{tabular}{|l|l|l|}
\hline & \multicolumn{1}{|c|}{ Definition } & \multicolumn{1}{|c|}{ Exemplar quote } \\
\hline $\begin{array}{l}\text { Repetition } \\
\text { of Content }\end{array}$ & $\begin{array}{l}\text { Students explain how content is initially } \\
\text { engaging but becomes "boring" as } \\
\text { activities continue to be repeated. }\end{array}$ & $\begin{array}{l}\text { It starts to get boring because you're staying } \\
\text { inside, not going outside or doing anything, and } \\
\text { then you're just here and doing nothing. }\end{array}$ \\
\hline $\begin{array}{l}\text { Student } \\
\text { Behavior }\end{array}$ & $\begin{array}{l}\text { Students explain how others' behavior } \\
\text { (i.e., bullying, disruption) limits their } \\
\text { desire to engage. }\end{array}$ & $\begin{array}{l}\text { I'm not very good at basketball because every } \\
\text { time I attempt to try and make a basketball shot, } \\
\text { people just straight-off say something like, 'you } \\
\text { don't [know] how to play basketball, or do you } \\
\text { know how to play basketball? Why can't you } \\
\text { make a three-point shot or a two-point shot?' }\end{array}$ \\
\hline
\end{tabular}

\section{Repetition of Program Content}

Students described how courses, though initially engaging, became "boring" over time as activities were repeated. For example, students can retake classes, meaning that they may choose to participate in music, dance, or basketball multiple times over the course of the school year. When asked why they may choose to disengage from a course, one student explained, "because in my music class we just keep doing the same thing, and it's boring." Thus, though programs initially excited students, the repetition of activities within the classes became tedious and "boring" over time. This highlights a lack of youth perspectives and autonomy in the development of OST program content and activities. When asked what would make the courses more engaging, students offered various ideas such as more gym time, more variety in course 
offerings, and more variety in the activities within the courses themselves. As such, it is clear that students had clear and specific ideas for enhancing program content to be more engaging.

\section{Student Behavior}

Student responses demonstrate how disruptive behavior and a lack of appropriate behavioral management inhibit their ability to fully engage. In particular, this disruptive behavior manifests itself as students being disrespectful to program staff or not showing up for group activities. When asked what inhibits their ability to fully engage, one student reported that students "act more annoyed towards the teachers and more mean," and another shared that "if they [students] don't like their class, they just don't come." Similarly, when asked why their peers might not engage in Starters, one student responded: "Some people just like to talk too much, and that's the ... reason why people wouldn't want to participate." These actions make it difficult for students to engage when their group mates aren't present, or teachers are having to discipline other students. In the most extreme forms, ostracized students reported experiencing bullying, which made them feel as if they didn't want to show up, much less engage in the activities.

\section{Discussion}

Historically, engagement has been discussed for students in a way that assumes all students experience engagement in the same way. However, researchers (Garcia Coll \& Szalacha, 2004; Spencer, 2008; Williams \& Deutsch, 2016) have brought attention to the fact that experiences within a youth development program, along with the meaning drawn from those experiences, are influenced by an individual's social identity. Therefore, it is important to consider that these commonly used concepts may look different in different populations. Results from this study extend prior literature by providing initial evidence around creating after-school programs designed specifically with the goal of engaging youth from historically marginalized communities. According to stage-environment fit theory (Eccles et al., 1993), students are most likely to engage in educational spaces where they feel a sense of belonging and their needs are met. Thus, it is crucial that youth development professionals consider youth perspectives around barriers to engagement when seeking to engage more students from historically marginalized communities. Below we provide programmatic recommendations to address the aforementioned youth-reported barriers. 


\section{Recommendations for Mitigating Youth-Identified Barriers}

In order to honor and center the perspectives of youth from racially marginalized communities who report limited access to programming (Afterschool Alliance, 2020), we advocate that programs should think critically about how they might address some of these youth-reported barriers to engagement in after-school programs. In this section, we highlight a few recommendations for mitigating the aforementioned barriers. Possible solutions include integrating youth perspectives, developing curriculum that fosters growth, and developing policies and building capacity in staff to engage in culturally relevant discipline techniques. By adopting such approaches, programs may be able to better support the ethnic minority youth that they currently serve, facilitating prolonged engagement. Williams and Deutsch (2016) caution against assumptions that all individuals of a specific racial or ethnic group share the same experiences. Although these recommendations align with what we have seen in the literature, it is important to note that not all youth from historically marginalized populations share these same struggles. However, we do believe that these types of programmatic changes would be beneficial for all youth.

\section{Integrating Youth Perspectives}

Historically, student voices, specifically those from racially minoritized backgrounds, have been marginalized in K-12 educational settings (Gonzalez et al., 2017). However, the integration of youth perspectives may be particularly influential for programs seeking to garner and maintain youth participation and engagement, especially for adolescents who experience a growing desire for autonomy (Akiva \& Horner, 2016; Denault \& Poulin, 2009). As evidenced by this research, youth have many perspectives and ideas that prove useful in programmatic design and evaluation. While many programs integrate youth perspectives in terms of content selection, it may prove beneficial to the engagement of youth from historically marginalized communities if their perspectives were considered in curriculum development and program design more broadly. For example, a program may harness youth perspectives by designing a leadership course that tasks the students with gathering their peers' opinions through participatory action research and then sharing them with program leadership and advisory boards. However, the critical part to this work involves the valuing of youth perspectives, in terms of making active efforts to integrate them into programmatic decisions. Another approach to the integration of youth perspectives is to select students and student graduates of the program to serve as full members of advisory boards, with voting and decision-making abilities. These steps move beyond just providing students with a seat at the table and demonstrate truly valuing youth as co-knowledge producers and developers (Clemons, 2020). An initial step 
that programs can take towards integrating youth perspectives is to conduct evaluations of this sort in which youth perspectives are centered and critically considered for continuous program improvement. These efforts can help to ensure that programs are engaging in better youth development work that meets the needs and desires of the students they serve. An important consideration in this work is to critically examine which voices are being integrated and which may be left out in this work, ensuring that efforts are taken to honor a representative sample of voices (Nasir \& Hand, 2006).

\section{Growth Fostering Curriculum}

In response to student-reported barriers around content repetition, programs might consider leveled approaches to classes that have students progress through difficulty (i.e., beginner, intermediate, and advanced) and provide courses that are designed specifically to increase the variety of activities. This leveled approach allows students to refine their skills over time and offers the opportunity for more advanced students to provide feedback and input on the curriculum development. By providing leveled approaches to courses through which students progress, program leaders could address the youth-reported barrier around repetition in content. In innovative programs, this may look like students engaging in design-thinking workshops that allow students leadership and ownership opportunities over course design and implementation. In other programs, more advanced students may act as mentors to support the development of their younger peers, a model that has demonstrated a positive impact for both mentees and older peer mentors (Karcher, 2007). In this way, programs can elevate the perspectives and values of students from historically marginalized communities while simultaneously avoiding the repetitive content that can serve as a barrier to their engagement experiences.

\section{Culturally Appropriate and Continuous Discipline Approaches}

In recent years, many schools have moved away from reliance on exclusionary discipline practices, instead adopting alternative approaches to discipline such as positive behavioral interventions and supports (PBIS), trauma-informed care (TIC), and culturally responsive-PBIS (CR-PBIS). Further, in light of the consistently diversifying PK-12 student population (Kena et al., 2016), various districts have developed and implemented equity audits focused on holding schools accountable for the equitable treatment of students, and training staff to work with diverse populations. At the after-school level, the adoption of such discipline training is often more difficult given funding limitations. As such, after-school educators may not be as prepared to work with student behavior in ways that acknowledges and supports students' cultural 
differences. However, given that student behavior surfaced as a student-reported barrier to engagement, it seems imperative that programs consider how they might prioritize the adoption of culturally appropriate discipline models (i.e., TIC, CR-PBIS) in order to curb some of these distracting and bullying-related behaviors in OST spaces. These discipline models are designed to provide students with needed support and redirection, encouraging engagement in programs and encouraging youth to support the engagement of their peers. Additionally, it is important that in adopting a culturally appropriate and supportive approach to discipline, programs provide educators with pragmatic and continuous training on how to properly implement such discipline interventions. Furthermore, results of the focus groups indicated that negative behaviors were often a sign that youth were feeling disengaged with programming. Rather than seeking to discipline youth, staff should consider negative behavior as a potential sign that programming needs to be adjusted to keep youth engaged. Without such considerations, disparate discipline outcomes may become present in after-school programs, further contributing to the inequitable educating of historically marginalized youth.

\section{Limitations}

While this data offers guidance in terms of youth-reported experiences, it is important to note that this data emerges from focus groups conducted with students at a singular after-school program, and therefore some of the findings may be related to the individual program's structure and influenced by social pressures within the focus group. Future work should use indepth interviews with students to determine if experiences and barriers are consistent across various programs and data collection methodologies. Further, this program worked largely with racially minoritized youth from historically marginalized communities, resulting in a racially and socio-economically homogenous sample. In order to expand upon our understanding of student engagement experiences, future research should build upon this work to consider how students' engagement and perceived barriers may differ based on the intersections of their individual identity characteristics (e.g., gender, race/ethnicity, SES). Together, this future research considers both individual and contextual differences that may emerge in students' engagement.

\section{Conclusion}

Taken together, these findings have implications for practice in that they inform programmatic adjustments that, if made, could better meet the needs of students from historically marginalized communities. For example, by working to integrate and value student perspectives, program staff can tap into adolescents' desire for autonomy and utilize it to promote continued engagement in courses that traditionally become repetitive over time. 
Adolescent students can also support the development of growth-fostering curriculum. Additionally, by adopting culturally appropriate discipline interventions, program leadership can mitigate students' experiences of behavioral disruptions and bullying that serve as barriers to engagement, while simultaneously avoiding historically exclusionary disciplinary approaches (i.e., out-of-school suspension). These efforts in combination can serve as initial steps to promoting the engagement of historically marginalized adolescents. However, it is important to note that many of these efforts require wrap-around support from policy makers as well as program funders. For example, funding agents need to make funding available for professional development on culturally responsive disciplinary approaches within an after-school setting. Additionally, administrators from after-school programs should consider reworking their policies and schedules in ways that facilitate the engagement of youth perspectives, such as inviting youth to these meetings and holding them after school hours, when youth are more able to attend.

Overall, findings from this study provide pragmatic solutions to mitigating adolescents' barriers to engagement and promoting continued youth engagement in high-quality after-school programs. This is important given that after-school programs are associated with a host of positive developmental outcomes (Durlak et al., 2010), and may be particularly supportive for youth from marginalized communities. As such, stakeholders on all levels should critically consider how to integrate these approaches in order to better engage youth that attend. Finally, this paper calls on the importance of extending issues of equity to the after-school setting. Although work is advancing within the school context, it is important to improve all contexts in which youth interact to ensure we are creating supportive contexts that align with the needs and strengths of youth from all communities.

\section{References}

Afterschool Alliance. (2020). America after 3PM: Afterschool programs in demand. (https://www.afterschoolalliance.org/documents/AA3PM-2014/AA3PM_Key_Findings.pdf)

Akiva, T., \& Horner, C. G. (2016). Adolescent motivation to attend youth programs: Amixed-methods investigation. Applied Developmental Science, 20, 278-293. (https://doi.org/10.1080/10888691.2015.1127162)

Bronfenbrenner, U. (1994). Ecological models of human development. In International Encyclopedia of Education (Vol. 3, $2^{\text {nd }}$ ed.). Elsevier. Reprinted in M. Gauvain \& M. Cole (Eds.), Readings on the development of children, ( $2^{\text {nd }}$ ed., pp.37-43). Freeman 
Carver, P. R., \& Iruka, I. U. (2006). National household education surveys program of 2005 After-school programs and activities (NCES 2006-076). U.S. Department of Education. National Center for Education Statistics.

Clemons, R. L. F. (2020). Leading with youth of color: Organizing for educational change. Journal of Youth Development, 15(5), 110-125. (https://doi.org/10.5195/jyd.2020.785)

Denault, A. S., \& Poulin, F. (2009). Predictors of adolescent participation in organized activities: A fiveyear longitudinal study. Journal of Research on Adolescence, 19, 287-311. (https://doi.org/10.1111/j.1532-7795.2009.00597.x)

Durlak, J. A., Weissberg, R. P., \& Pachan, M. (2010). A meta-analysis of after-school programs that seek to promote personal and social skills in children and adolescents. American Journal of Community Psychology, 45, 294-309. (https://doi.org/10.1007/s10464-010-9300-6)

Deutsch, N. (Ed.). (2017). After-School programs to promote positive youth development: Integrating research into practice and policy (Vol. 1). Springer.

Eccles, J. S., Wigfield, A., Midgley, C., Reuman, D., Iver, D. M., \& Feldlaufer, H. (1993). Negative effects of traditional middle schools on students' motivation. The elementary school journal, 93(5), 553574.

Finn, J. D. (1989). Withdrawing from school. Review of Educational Research, 59, 117-142. (https://doi.org/10.3102/00346543059002117)

Finn, J. D. (1993). School engagement and students at risk. (Report No. NCES-93-470). U.S. Department of Education, National Center for Education Statistics.

Flores, A. (2007). Examining disparities in mathematics education: Achievement gap or opportunity gap? The High School Journal, 91, 29-42.

Fredricks, J. A., Blumenfeld, P. C., \& Paris, A. H. (2004). School engagement: Potential of the concept, state of the evidence. Review of Educational Research, 74, 59-109. (https://doiorg/10.3102/00346543074001059)

Fredricks, J. A., \& McColskey, W. (2012). The measurement of student engagement: A comparative analysis of various methods and student self-report instruments. In S. Christenson, A. Reschly, \& C. Wylie (Eds.), Handbook of research on student engagement (pp. 763-782). Springer. (https://doi.org/10.1007/978-1-4614-2018-7_37)

García Coll, C., \& Szalacha, L. (2004). The multiple contexts of middle childhood. The Future of Children, $14(2), 80-97$.

Gast, M. J., Okamoto, D. G., \& Feldman, V. (2017). "We only speak English here": English dominance in language diverse, immigrant after-school programs. Journal of Adolescent Research, 32, 94- 121. (https://doi.org/10.1177/0743558416674562) 
Gonzalez, T. E., Hernandez-Saca, D. I., \& Artiles, A. J. (2017). In search of voice: Theory and methods in K-12 student voice research in the US, 1990-2010. Educational Review, 69(4), 451-473. (https://doi.org/10.1080/00131911.2016.1231661)

Gray, D. L., Hope, E. C., \& Matthews, J. S. (2018). Black and belonging at school: A case for interpersonal, instructional, and institutional opportunity structures. Educational Psychologist, 53(2), 97-113. (https://doi.org/10.1080/00461520.2017.1421466)

Hill, S., \& Vance, F. (Eds.). (2019). Changemakers!: Practitioners advance equity and access in out-ofschool time programs. IAP.

Hughes, D. L., Del Toro, J., \& Way, N. (2017). Interrelations among dimensions of ethnic-racial identity during adolescence. Developmental Psychology, 53(11), 2139-2153. (https://doiorg/10.1037/dev0000401)

Karcher, M. J. (2007). Cross-age peer mentoring. Youth Mentoring: Research in Action, 1(7), 3-17. Kena, G., Hussar, W., McFarland, J., De Brey, C., Musu-Gillette, L., Wang, X., Zhang, J., Rathbun, A., Wilkinson-Flicker, S., Diliberti, M., Barmer, A., Bullock Mann, F., \& Dunlop Velez, E. (2016). The Condition of Education 2016. (Report No. NCES 2016-144). U.S. Department of Education, National Center for Education Statistics. (https://nces.ed.gov/pubs2016/2016144.pdf)

Kochanek, J., \& Erickson, K. (2020). Interrogating positive youth development through sport using critical race theory. Quest, 72(2), 224-240. (https://doi.org/10.1080/00336297.2019.1641728)

Lauer, P. A., Akiba, M., Wilkerson, S. B., Apthorp, H. S., Snow, D., \& Martin-Green, M. (2006). Out-ofschool-time programs: A meta-analysis of effects for at-risk students. Review of Educational Research, 76, 275-313. (https://doi.org/10.3102/00346543076002275)

Ma, T., Yu, M., Soto-Lara, S., Simpkins, S. (2020). Latinx adolescents' peer ethnic discrimination in afterschool activities and activity experiences. Journal of Youth Development, 15(6), 1-27. (https://doi.org/10.5195/jyd.2020.938)

Mahoney, J. L., Vandell, D. L., Simpkins, S., \& Zarrett, N. (2009). Adolescent out-of-school activities. In R. M. Lerner \& L. Steinberg (Eds.), Handbook of adolescent psychology (3 ${ }^{\text {rd }}$ ed., pp. 228-269). Wiley.

Nasir, N. I. S., \& Hand, V. M. (2006). Exploring sociocultural perspectives on race, culture, and learning. Review of educational research, 76(4), 449-475.

Onwuegbuzie, A. J., Leech, N. L., \& Collins, K. M. (2012). Qualitative analysis techniques for the review of the literature. The Qualitative Report, 17, 1-28. (http://www.nova.edu/ssss/QR/QR17/onwuegbuzie.pdf)

Sjogren, A. L., Bae, C. L., Deutsch, N. L., Zumbrunn, S., \& Broda, M. (2021). Afterschool engagement: A mixed methods approach to understanding profiles of youth engagement. Applied Developmental Science, 1-19. (https://doi.org/10.1080/10888691.2021.1947140) 
Journal of Youth Development | http://jyd.pitt.edu/ | Vol. 16 Issue 5 DOI 10.5195/jyd.2021.1068 Engagement of Historically Marginalized Youth

Sjogren, A. L., Zumbrunn, S., Broda, M., Bae, C. L., \& Deutsch, N. L. (2021). Understanding afterschool engagement: Investigating developmental outcomes for adolescents. American Journal of Community Psychology, 1-14. (https://doi.org/10.1002/ajcp.12554)

Skiba, R. J., Michael, R. S., Nardo, A. C., \& Peterson, R. L. (2002). The color of discipline: Sources of racial and gender disproportionality in school punishment. The Urban Review, 34(4), 317-342. (https://doi.org/10.1023/A:1021320817372)

Spencer, M. B. (2008). Phenomenology and ecological systems theory: Development of diverse groups. In W. Damon \& R. M. Lerner (Eds.), Child and adolescent development: An advanced course (pp. 696-740). Wiley.

Vanneman, A., Hamilton, L., Anderson, J. B., \& Rahman, T. (2009). Achievement gaps: How black and white students in public schools perform in mathematics and reading on the national assessment of educational progress. Institute for Education Sciences. (https://files.eric.ed.gov/fulltext/ED505903.pdf)

Wang, M. T., Fredricks, J. A., Ye, F., Hofkens, T. L., \& Linn, J. S. (2016). The math and science engagement scales: Scale development, validation, and psychometric properties. Learning and Instruction, 43, 16-26. (http://dx.doi.org/10.1016/j.learninstruc.2016.01.008)

Williams, J., \& Deutsch, N. (2016). Beyond between-group differences: Considering race, ethnicity, and culture in research on positive youth development programs. Applied Developmental Science, 20(3), 203-213. (http://dx.doi.org/10.1080/10888691.2015.1113880) 